\title{
Teaching ethics in Canadian gastroenterology
}

\author{
Guido Van Rosendaal MD
}

A firm foundation in medical bioethics is essential to the education of any physician. The relative importance of specific ethical principles may vary with the physician's specialty, depending on the nature of the problems dealt with or the services provided in each discipline. The working knowledge in ethics required of a gastroenterologist is different, for example, from that needed by an intensivist or a psychiatrist. It is with this context in mind that Malhotra and Ottaway, in this issue of the Journal (pages 315-317), propose the creation of a national curriculum in bioethics specific to gastroenterology.

The Royal College of Physicians and Surgeons of Canada (RCPSC) requires the inclusion of bioethics teaching in all Canadian residency programs (1). However, no parallel mandate exists for the continuing education of practicing gastroenterologists. The result may be that those of us who teach residents have an inadequate knowledge of ethics. Few of us have had more than a passing education in this area and we are unlikely to put much effort into refreshing and updating this knowledge, given the pressures of keeping up with the clinical and scientific literature. But we work in an environment of health and health care which is increasingly managed according to the principles and values of business, and this is having a profound effect on the practice of medicine as we have known it. A sound grasp of ethical principles, therefore, is increasingly important to getting us through the current paradigm shifts in the health system and the practice of medicine

In response to the major systemic changes which were afoot, the RCPSC undertook an inventory of the skills that would be required of Canadian physicians in the new millennium in its 'CanMeds 2000' project and has since moved to ensure their implementation (2). In this undertaking, they rearticulated the importance of professionalism to medicine, including a foundation in ethics. In addition, several prominent physicians have recently written about the need for a renewal of medical professionalism at an individual and an organizational level (3-6). Whether we are residents, teachers or practitioners, we should accept this good advice.

What should an ethics curriculum for Canadian gastroenterologists look like? Malhotra and Ottaway's findings provide some initial guidance, but the process of generating the right curriculum requires more reflection and the input of experts in the area. I will suggest a few elements that might potentially be added to the list.
Social justice, or simply 'justice', is a long-accepted pillar of medical bioethics. This principle emerges in the CanMeds 2000 project under the 21st century physician's role of 'manager'. Within the realm of 'management' the physician is understood to bear responsibility for the husbandry of health resources on a population basis. The need to deliver on this principle, ie, to ensure that available resources are expended fairly across the population, constitutes an important new element in the role we, as physicians, play in society. It represents a fundamental change in the way in which we work, an expansion of our traditional notion of the 'practice of medicine'.

Incorporating 'justice' into the new paradigm of medical practice will pose an increasing challenge as potential services to be provided outstrip the resources available. For example, the implementation of the recently published guidelines for colorectal cancer screening by Leddin et al (7) requires a substantial increase in needed resources. In the absence of these resources should we, as individual gastroenterologists, begin colonoscopic screening of the general population over the age of 50 years, recognizing that this service will be provided unevenly across the population and that providing it is likely to delay access to care for other individuals with gastrointestinal symptoms? This, and similar questions having to do with resource allocations are uncomfortable ones for most of us, ones that we have not viewed to be our responsibility in the past. It is essential, however, that we accept a role in such decisionmaking. Otherwise, we risk losing the focal position we have traditionally held in the Canadian health system.

The ethics surrounding percutaneous endoscopic gastrostomy feeding tube placement also require specific consideration in a gastroenterology curriculum. That "ethical aspects of artificial nutrition" ranked near the bottom of the ethical issues list for both residents and staff in the Malhotra and Ottaway study likely reflects the fact that participants had little time to reflect on the issues and that the list of principles included in their questionnaire were of a general and conceptual nature. Gifting to physicians by industry is another issue that should be included.

Once created, such a curriculum could be effectively presented on a national level, as Malhotra and Ottaway suggest. Using a case-based approach to do this is also an excellent idea. Perhaps the most effective cases on which to base this teaching are the ones we see in practice on a daily basis. If we are to

Departments of Community Health Sciences and Medicine, Health Science Centre, University of Calgary, Calgary, Alberta

Correspondence: Dr Guido Van Rosendaal, Community Health Sciences and Medicine, Health Science Centre, University of Calgary, 3330 Hospital Drive Northwest, Calgary, Alberta T2N 4N1. Telephone 403-210-9363, fax 403-270-7307, e-mail gurosend@ucalgary.ca 
use these real life examples in an effective way, we must ensure that those who teach our residents are sufficiently steeped in bioethics and committed to undertaking this teaching.

The curriculum for pediatric gastroenterology will require separate consideration and will undoubtedly look somewhat different from that created for the adult gastroenterology

\section{REFERENCES}

1. The Royal College of Physicians and Surgeons of Canada. Bioethics education. <http://rcpsc.medical.org/ethics/index.php> (Version current at April 6, 2004).

2. The Royal College of Physicians and Surgeons of Canada's Canadian Medical Education Directions for Specialists 2000 Project. Skills for the New Millennium: Report of the Societal Needs Working Group. <http://rcpsc.medical.org/canmeds/ canmed_e.html> (Version current at April 6, 2004).

3. Pellegrino ED, Relman AS. Professional medical associations: Ethical and practical guidelines. JAMA 1999;282:984-6.

4. Rothman DJ. Medical professionalism - focusing on the real issues. N Engl J Med 2000;342:1284-6. stream. Perhaps the concept of a national approach to curriculum development and implementation could also usefully be applied in other areas of gastroenterology residency and continuing medical education curricula, such as quality improvement and 'management.' Good luck to those who take the initiative in developing this idea!

5. ABIM Foundation, American Board of Internal Medicine; ACPASIM Foundation, American College of Physicians-American Society of Internal Medicine; European Federation of Internal Medicine. Medical Professionalism in the new millennium: A physician charter. Ann Intern Med 2002;136:243-6.

6. Wynia MK, Latham SR, Kao AC, Berg JW, Emanuel LL. Medical professionalism in society. N Engl J Med 1999;341:1612-6

7. Leddin D, Hunt R, Champion M, et al. Canadian Association of Gastroenterology and the Canadian Digestive Health Foundation: Guidelines on colon cancer screening. Can J Gastroenterol 2004;18:93-9. 


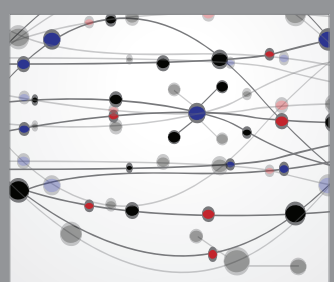

The Scientific World Journal
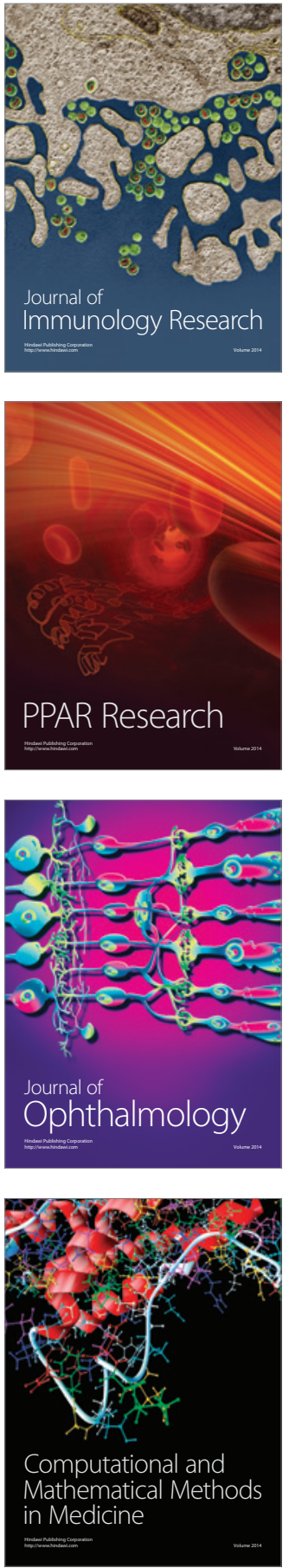

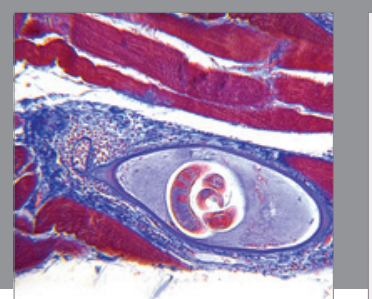

Gastroenterology Research and Practice

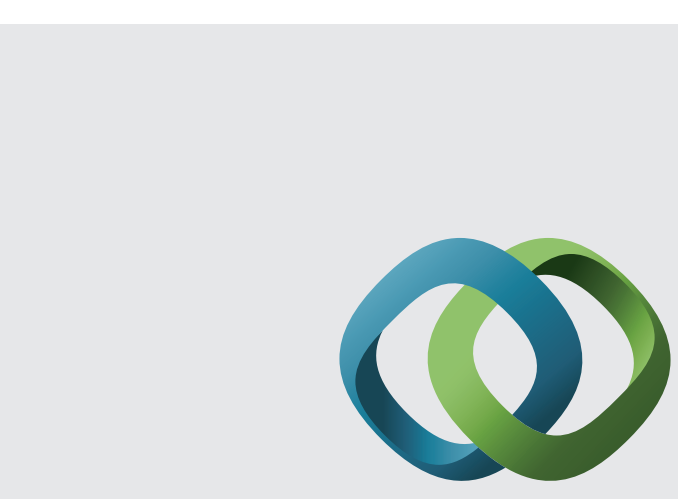

\section{Hindawi}

Submit your manuscripts at

http://www.hindawi.com
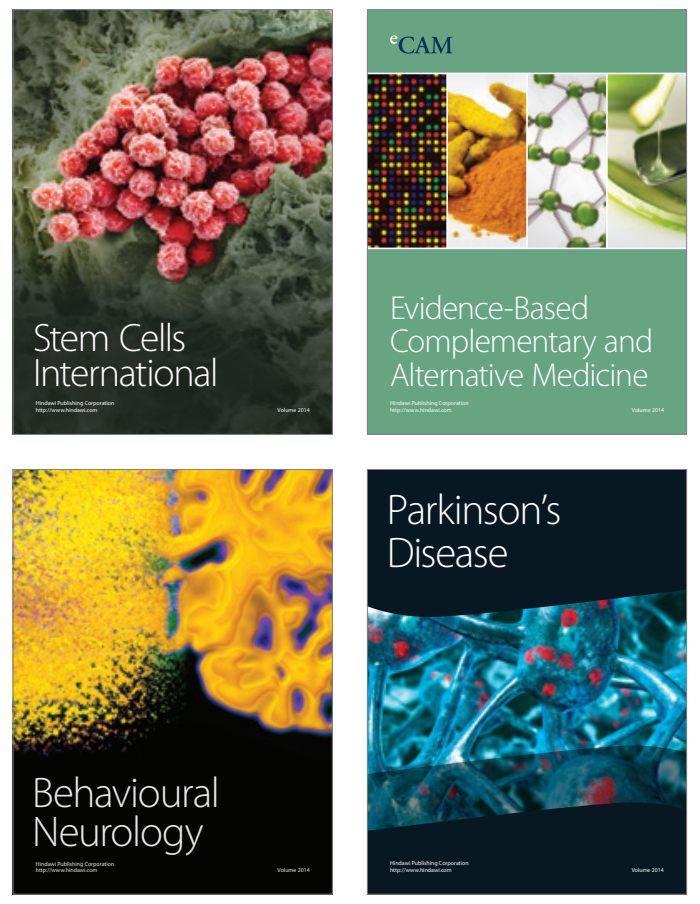
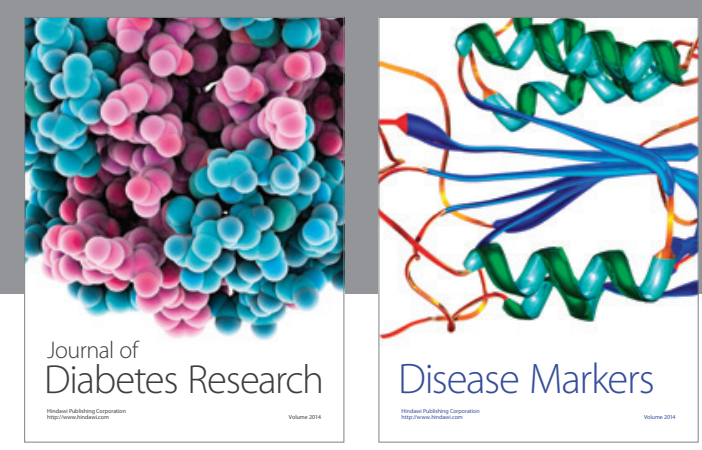

Disease Markers
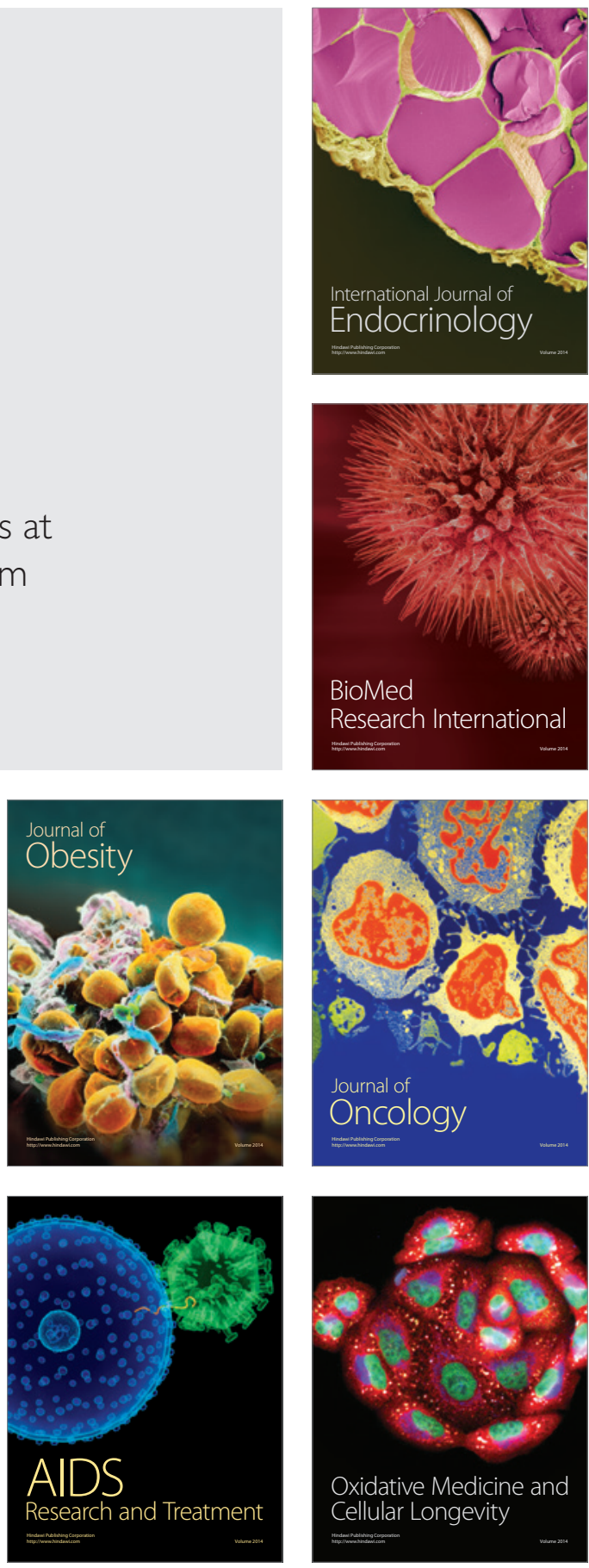